Joaquín Fermandois: Mundo y Fin de Mundo: Chile en la Política Mundial 1900-2004.

(Santiago: Ediciones Universidad Católica de Chile, 2005, 638 páginas.)

\title{
MUNDO Y FIN DE MUNDO
}

\section{David Gallagher}

$\mathrm{E}$

1 último libro de Joaquín Fermandois es en el fondo una historia política, económica y social de Chile entre 1900 y 2004, con una buena introducción que resume la herencia de la colonia y del siglo diecinueve. Esta historia está enfocada desde el punto de vista de la relación de Chile con otros países. Fermandois demuestra cómo Chile, a pesar de su aparente distancia y aislamiento, es una parte integral del mundo. Su economía, incluso en los períodos en que se intenta cerrarla relativamente, depende de los vaivenes de la economía internacional: como toda economía, se podría agregar, salvo que en el caso de la chilena la dependencia (valga la palabra sin connotaciones peyorativas cepalianas) es más aguda por ser Chile un país de mercado chico y de ventajas comparativas excepcionales para producir productos estelares de exportación, productos que dependen de la demanda internacional. En cuanto a su vida política, Chile está insertado desde el siglo diecinueve en las grandes corrientes internacionales. Su

DAvid GaLlagher nació en Valparaíso en 1944. Educado en Oxford, fue luego profesor de literatura latinoamericana del St. Antony's College de esa misma Universidad. Ha publicado Modern Latin American Literature (Oxford University Press, 1973), Improvisaciones (Centro de Estudios Públicos, 1992), Otras improvisaciones (El Mercurio-Aguilar, 2004) y numerosos ensayos. Fue Director del Morgan Grenfell International \& Co. Ltd. Actualmente es socio de ASSET-CHILE y combina sus actividades como ensayista y crítico con las de banca de inversiones. Colabora con TLS (The Times Literary Supplement) y es columnista de El Mercurio de Santiago. Es miembro del Consejo Directivo del Centro de Estudios Públicos. 
independencia y sus primeros decenios republicanos son hijos de la "era de las revoluciones” que marca a Europa y Estados Unidos entre 1776 y 1848². El siglo veinte será marcado por la lucha internacional entre izquierdas y derechas. En todo esto Chile es a la vez una simple parte del mundo y un caso particular dentro de él, un caso particular con especificidades y diferencias propias que son acentuadas, a veces, por la lejanía. Fermandois reconoce que en esto en el fondo Chile se parece a cualquier país:

La sensación de ser parte de un mundo como la de estar solitarios, o aislados, marcarían un contrapunto que se arrastra hasta comienzos del siglo XXI. Pero ¿no es tensión la mirada de toda sociedad ante el mundo? ${ }^{2}$.

La originalidad de esta historia de Chile es que los acontecimientos analizados son siempre vistos en función de este contrapunto, son siempre situados en relación con su particularidad nacional y la influencia internacional, que, en fin de cuentas, Fermandois considera mayor en Chile que en otros países.

Todo país, toda sociedad, puede ser visto como una combinación entre apertura y cierre frente al mundo. Sólo que en Chile esto parece ser de un grado mayor, teniendo en cuenta la gran influencia que la política mundial tuvo en la conformación de la cultura política chilena a lo largo del siglo $\mathrm{XX}^{3}$.

Quizás el hecho más original o particular en la historia de Chile, y uno de los que más marcan nuestras relaciones internacionales hasta ahora, es la Guerra del Pacífico. Según Fermandois, sus epopeyas

crearon una narración mítica en Chile que penetró profundamente en lo que se podría llamar la "cultura chilena”, con todos los problemas que ofrece el uso de ese concepto. Le dio a Chile una extraordinaria autoconciencia y seguridad en sí mismo como Estado Nacional.

La Guerra del Pacífico operó en este sentido como el más importante —más visible en todo caso- “cemento de la sociedad"4.

\footnotetext{
${ }^{1}$ P. 24.

2 P. 43.

${ }^{3}$ P. 52

${ }^{4}$ P. 36.
} 
Fermandois traza con maestría los problemas diplomáticos con que Chile ha tenido que lidiar para preservar los resultados de una guerra que rápidamente le dio al país, en algunos círculos internacionales, el apelativo de 'Prusia de Sudamérica'. De allí en adelante Chile se fue aferrando cada vez más a la legalidad internacional como opción de política exterior, y el desarrollo de la historia del país se fue asimilando cada vez más a las grandes corrientes internacionales, entendidas éstas por cierto como las provenientes de Europa, Estados Unidos y, en menor grado, del resto de América Latina; la conciencia de la importancia del Asia es un fenómeno relativamente nuevo en Chile, y es compartido todavía sólo por pocos.

Fermandois a lo largo del libro muestra cómo las ideas económicas con que se gobierna el país son influenciadas por ideas en boga en el mundo en su momento, pero aún más por eventos económicos mundiales que afectan a la economía chilena, porque sube o baja la demanda por sus productos y sube o baja la oferta de capital. La economía chilena era relativamente abierta y el sistema económico era básicamente liberal hasta 1914 (si bien había un aspecto sui generis: el Estado vivía en gran medida del impuesto a la exportación del salitre, lo que le permitía prescindir de otros impuestos). Fermandois explica cómo la Primera Guerra Mundial empezó a minar el liberalismo. Con la guerra el comercio internacional se volvió más difícil: Inglaterra con sus Listas Negras "prohibía comerciar con quienes directa o indirectamente lo hacían con el enemigo”. Ya en 1917 Agustín Edwards vaticina "el fin de la era liberal” y el acercamiento del "socialismo de Estado como un mal necesario"6. Mucho más devastador en este sentido es el efecto de la Gran Depresión que, desde 1929, destruye la economía chilena. Fermandois cita un informe de la época, de la Liga de las Naciones, que estima que Chile fue el país que más sufrió en el mundo: entre 1929 y 1932 las exportaciones bajaron en un estruendoso 88\%. Fermandois estima que en el mismo período el PGB puede haber disminuido "en cerca de un 50\%”7. En 1932 Chile era un país en ruinas, que había tenido que renegar de su deuda externa. En las lapidarias palabras de Fermandois:

La resonancia externa a la crisis fue de arrogante y despectivo repudio al carácter de Chile. Al leer los documentos, el historiador experimenta el bochorno de que su país era, a partir de ese momento, considerado como un 'don Nadie'8.

\footnotetext{
5 P. 80.

6 P. 79.

7 P. 109.

${ }^{8}$ P. 112.
} 
Fermandois enseguida cita al Cónsul General de Estados Unidos cuando solemnemente avisa a Washington en noviembre de 1933 que hay "que dar una triste despedida a Chile, el país con un sombrío futuro pero con inolvidable pasado". 9

No es raro que en estas circunstancias se haya producido un cambio de paradigma económico en Chile. Es la época del New Deal de Roosevelt, y del apogeo de Keynes: el cambio es mundial. Cabe decir que en Chile ese cambio se dio al comienzo en forma bastante particular, bajo la tutela del Ministro de Hacienda Gustavo Ross (1932-1938). Fermandois ya había escrito un libro muy detallado sobre este período ${ }^{10}$, y ahora le dedica un excelente capítulo. En realidad Ross, conocido como "el mago de las finanzas”, llevó a cabo una política económica creativa, pragmática, para sacar a la economía chilena del hoyo y encaminarla a un desarrollo sostenido, sin nunca abandonar los principios de una economía de mercado. Hubo fuertes incentivos a la construcción y aranceles proteccionistas, y un concepto de asociación y cooperación entre el Estado y los empresarios, pero se mantuvo un riguroso equilibrio fiscal y "con todo, en el ambiente de los treinta, la estrategia de Ross estaba más orientada a insertarse nuevamente en la economía de mercado"11. El intervencionismo era para Ross un expediente pragmático para "cruzar el desierto de la Depresión”, más que una estrategia de desarrollo de largo plazo $^{12}$. De vez en cuando la derecha chilena ha producido a personajes así, personajes creativos sin temor a olvidarse en el corto plazo de los textos clásicos para superar una crisis, pero con la idea de después retomarlos: pienso en un Hernán Büchi en 1984-1988, con su pragmatismo y creatividad heterodoxa. La estrategia de desarrollo sólo cambió en forma profunda hacia una de sustitución de importaciones y de empresas estatales con el triunfo de Aguirre Cerda sobre Ross en 1938. Ganó por 4.000 votos, en esa época el 1\%. El largo y empobrecedor período de desarrollo hacia adentro, que culminó en 1973, tal vez se habría mitigado o incluso evitado si Ross hubiera tenido la oportunidad de consolidar su obra de recuperación a su manera.

Fermandois constata la profunda influencia que tiene en Chile a partir de 1920, y más aún a partir de 1938, la lucha global entre izquierda y

\footnotetext{
${ }^{9}$ P. 112.

10 Abismo y cimiento. Gustavo Ross y las relaciones entre EE.UU. 1932-1938. (Santiago, 1977).

11 P. 119.

12 P. 124.
} 
derecha, con una izquierda cada vez más marxista a partir del triunfo de la Revolución Rusa en 1917. En esto hay un aspecto muy interesante. En Chile se da la lucha global entre democracia occidental y marxismo hasta el fin mismo de la Guerra Fría. En cambio a diferencia de Argentina, donde desemboca en peronismo, el fascismo europeo se manifiesta en Chile en forma muy mitigada. Por otro lado los grandes movimientos latinoamericanos como el de la Revolución Mexicana o el mismo peronismo dejan bastante indiferentes a los chilenos: para que un país latinoamericano tuviera influencia en Chile hubo que esperar el surgimiento de un marxista como Fidel Castro ${ }^{13}$. Es como si en Chile hubiera una medida inconsciente de la universalidad de las grandes corrientes de ideas, como si rechazáramos fenómenos políticos cuya narrativa se fundamenta demasiado en la anécdota y no en la lógica, como si estuviéramos dispuestos sólo a socializar abstracciones defendibles en cualquier lugar y en cualquier momento, y no sólo en el contexto de un anecdotario criollo.

La capacidad de Chile de socializar las grandes abstracciones ideológicas de corte más universal convirtió al país en un laboratorio internacional. Primero vino el 'Estado de compromiso', el ‘modelo Corfo', el ‘desarrollo hacia adentro’, todo administrado por un sistema político en que la competencia se libraba a través de la incontinente satisfacción de demandas sociales. El resultado, hacia 1955, cuando fue contratada la misión Klein Sacks, para estabilizar la economía, fue una inflación que era estudiada en todas las universidades del mundo por ser casi única en sus dimensiones, en un país en que había una brecha cada vez más grande entre las crecientes demandas sociales y una decreciente capacidad de la economía para satisfacerlas. Después vienen, en las elecciones de 1958, 1964 y 1970, las clásicas batallas entre las fuerzas de 'occidente' y las del 'bloque soviético'. Fermandois revela el altísimo grado de intervención internacional que hay en esas elecciones, sobre todo en la de 1964, donde paradójicamente la ayuda norteamericana al candidato de 'occidente' fue mayor aún que en 1970. Es que en Chile en todas estas elecciones se está librando una batalla crucial de la Guerra Fría y se está viviendo una coyuntura similar a la de la política de muchos países europeos, sobre todo de países mediterráneos como Francia, Italia o Grecia, donde hay intermitentemente una izquierda con fuerte influencia marxista, que amenaza con llegar democráticamente al poder, con todo lo que eso significa para la seguridad de una alianza como la OTAN. Que en Chile se produzca el precedente de un

\footnotetext{
${ }^{13}$ Pp. 74-75.
} 
gobierno marxista libremente elegido pasa a ser un tema de preocupación o de esperanza internacional, según el espectro con que se mire.

El período de 1938-1973 no sólo es uno en que en Chile se libran cada vez más batallas de índole global. Es un período en que en el país se espera cada vez más que la solución de los problemas económicos nacionales provenga del exterior. El correlativo es que los males del país también provienen del exterior. Es lo que Fermandois llama la 'era del subsidio', la era de las ideas cepalianas.

Este mundo de ideas nutría una profunda desconfianza hacia la capacidad espontánea de la economía de mercado, o "capitalismo" si se quiere, de poder impulsar el desarrollo. Obedecía a la idea de que en la naturaleza de las grandes economías, y de las grandes potencias que la representaban, se escondía algo así como un "reparto injusto" de las riquezas. Anidaba en su corazón lo que después se llamó "estructuralismo" y, en un desarrollo posterior, consecuencia y paralelo a la vez, la "teoría de la dependencia". Su remoto origen está en las ideas políticas en torno a los autoritarismos de Europa "subdesarrollada" de los 1930. Con todo, en Chile la práctica y el lenguaje provienen del desarrollo económico y político de los treinta, y eran casi unánimemente sostenidos ${ }^{14}$.

La política exterior chilena se dedica cada vez más a conseguir ayuda externa, en la forma sobre todo de préstamos de agencias internacionales como el Eximbank de Estados Unidos. A eso se abocan no sólo los gobiernos radicales sino, después, los de Alessandri y de Frei Montalva. Éstos al pedir ayuda se nutren justamente de la Guerra Fría, postulando a Chile como un país ejemplar en peligro, un país que merece ser ayudado y al que a los donantes les conviene ayudar, para que no vaya a caer en manos de los comunistas. Fermandois muestra cómo a veces a los presidentes pedigüeños les va bien, pero también se regocija en describir instancias en que les va mal. Cita unas ácidas referencias que hace en sus memorias Dean Acheson a viajes de presidentes sudamericanos llenos de peticiones, como el de Juan Antonio Ríos a Estados Unidos en 1945, o las severas palabras con que Ludwig Erhard, el Canciller alemán, amonesta a Frei en 1967, cuando le dice que la llave del desarrollo no está en la asistencia externa, sino en el ahorro y el combate a la inflación. Allende también es un exponente de la mentalidad de subsidio. Lo es cuando se queja de lo que le han 'quitado' a Chile los extranjeros (a través del 'bloqueo invisible' o de

\footnotetext{
${ }^{14}$ P. 178.
} 
las 'utilidades excesivas' de las multinacionales), y lo es cuando va a pedirle ayuda al "hermano mayor”, a la Unión Soviética, en $1972^{15}$. Una vez más Chile es un país ejemplar, esta vez uno que está a riesgo de ser "perdido" más bien por el mundo comunista. Una vez más, el presidente en gira es defraudado: los soviéticos le brindan una ayuda francamente exigua.

Quizás el gobierno chileno que más alejado estuvo de los paradigmas internacionales fue el de Pinochet. Reiteradamente Fermandois destaca un hecho curioso: la incapacidad no sólo de los militares sino de casi toda la derecha chilena de entender por qué ese gobierno produjo tanto rechazo internacional. Creían que Chile sería celebrado como el país que, en los confines de la tierra, había dado un golpe en defensa del Occidente: "los militares estaban convencidos que iban a ser aplaudidos por el mundo occidental y el antimarxismo en América Latina"16. Como dice Fermandois, esto revela poco conocimiento del mundo exterior de parte de la derecha, de una derecha que quizás nunca estuvo — ni está ahora — tan globalizada como la izquierda, a pesar de ser paradójicamente la fuerza que reabrió la economía chilena, generando más interacción real con el exterior que cualquier ideología política. Paradójicamente el gobierno chileno más aislado de la historia fue el que había producido más asociación privada con el exterior de lo que se había visto jamás.

¿Pero por qué fue tan repudiado el gobierno de Pinochet, a pesar del reconocimiento empresarial internacional a los éxitos económicos? Por las torturas y desapariciones, desde luego: de éstas se sabía en Londres, Roma o Washington muy rápido: hoy día en esas capitales les cuesta creer que en Chile haya gente en la derecha que se esté enterando sólo ahora. En esas capitales se sabía todo porque había prensa informada, y porque entre los torturados había ciudadanos extranjeros, como la inglesa Sheila Cassidy ${ }^{17}$. Uno de los primeros desaparecidos fue el padre Woodward, un sacerdote inglés torturado en la Esmeralda. También se sabía todo por obra de los exiliados. Pinochet despachó al mundo a miles de personas que podríamos llamar antiembajadores: es increíble que él y su gente no se hayan percatado de lo destructores que iban a ser de su imagen, dado que eran además muchos de ellos chilenos de alto vuelo, muy bien conectados. Enseguida hubo esos crímenes espectaculares, cometidos en Buenos Aires, Washington y Roma. Y la fuerza del mito de Allende como marxista elegido democráticamente. Aun gente que detestaba el marxismo pensaba — quizás

\footnotetext{
15 P. 386.

16 P. 417.

17 P. 429.
} 
ingenuamente- que había que combatirlo en las urnas. Finalmente las imágenes y los cuentos que salían de Chile en 1973 se parecían demasiado a los que habían salido de Grecia, la 'cuna de la democracia', durante el golpe de los coroneles en 1967. Fermandois nos recuerda, con el asombro que se merece, el recurrente espectáculo de uno y otro canciller de Pinochet despedido por no haber logrado suficientes 'avances' en materia, por ejemplo, de las condenas rituales que hacía cada año la ONU.

Una de las delicias de este libro sobre la inserción de Chile en el mundo es la descripción que hace Fermandois de las giras presidenciales, las de presidentes foráneos a Chile, y las de presidentes chilenos al exterior, no en la época de un Frei Ruiz-Tagle o un Lagos, en que estas giras se volvieron pan de cada día, sino cuando era más difícil o menos común viajar. Está el viaje del presidente Ríos, ya enfermo, en 1945, que duró nada menos que 60 días. Está la venida de la Reina Isabel. Está la venida de Charles de Gaulle.

Arribó a Valparaíso una mañana radiante a bordo del crucero Colbert. A Alessandri no le quedaba más de un mes en la presidencia, e hizo el papel estelar para estar digno de la altura de uno de los grandes estadistas del siglo XX. Podía conversar en francés con el huésped. De Gaulle, de 74 años, con problemas de salud, pasando por Chile como parte de una gira por once países latinoamericanos, De Gaulle, estoicamente, hizo un gran papel, recibido y adorado por multitudes y supo expresar con elegancia diversos halagos a Chile, aunque algunos con sinceridad. Jorge Alessandri quiso destacar el vanguardismo político de De Gaulle, para ponerse en su estela ${ }^{18}$.

¡Cuán distinta esa épica visita de la hecha recién por Chirac! Finalmente está el viaje de Frei Montalva a Europa en 1965.

Si Alessandri probablemente se sentía incómodo en el mundo internacional, Frei resplandecía y aun se refugiaba en él. Desde su primer viaje de estudiante escaso de recursos, en 1934, hasta la llegada a Londres a la Victoria Station, donde lo aguardaba en carroza la reina Isabel II, también en la cúspide de su popularidad e irradiación, para conducirlo a Buckingham Palace. Era un ascenso meritocrático en más de un sentido ${ }^{19}$.

\footnotetext{
18 P. 290.

${ }^{19}$ P. 308.
} 
En citas como las dos anteriores el lector puede percatar el encanto con que Fermandois evoca escenas del pasado, haciéndonos revivirlas como en la mejor de las crónicas. Su libro tiene el mérito en general de hacernos vivir el día a día de la historia de Chile en el siglo XX, de obligarnos a compartir los procesos de toma de decisiones como si no tuviéramos el beneficio del conocimiento posterior. Fermandois en suma es un gran narrador.

El libro cuenta la historia de Chile con objetividad, con poca intromisión del autor. Muy de vez en cuando el autor se permite deslizar una opinión, aunque sea en forma de ironía, aunque sea con la más elegante reticencia. Por ejemplo, hablando de la aparición de la hegemonía estadounidense a finales de la Segunda Guerra Mundial, se revela relativamente pro Estados Unidos, pero en una prosa fina que cubre todos los posibles flancos de crítica y de autocrítica. Dice inimitablemente Fermandois:

La tormenta, ¿fue un tormento? Todo depende del tipo de "hegemonía" de que se hable. La ejercen, cada uno en su nivel, pequeños y poderosos. La de estos últimos, finalmente, será benigna o constituirá una férula pesada en relación a la complejidad y liberalidad de su civilización. Por más que Estados Unidos en un rapto de inocencia homicida pueda arrasar una ciudad con un nuevo producto de la ciencia, para que los muertos — combatientes y, sobre todo, civiles- sean una disuasión a la continuidad de la guerra, ofrecía nueva y hasta mejor vida al vencido. No se podía decir lo mismo de otros participantes activos del conflicto. Fue una suerte que ese fuera el tipo de hegemonía en el que Chile se encontró ${ }^{20}$.

Así de bien está escrito un libro que es un compendio único de las relaciones de Chile y el mundo en el siglo XX, y como tal, a la vez, una gran historia de Chile en ese siglo. 